versity. This year, for the first time, the UGC has also taken into account unit costs, and staff : student ratios. Veterinary students come out as the most expensive, with a unit cost of $£ 1,136$, and social scientists are the cheapest at $£ 255$. The staff : student ratio is most favourable in veterinary science, at $1: 4 \cdot 6$, and least favourable in education, at $1: 12 \cdot 5$. Physical science, the report says, has a unit cost of $£ 376$ and staff : student ratio of $1: 11 \cdot 3$, but biological sciences are more expensive, with unit costs of $£ 518$ and staff : student ratios of $1: 8 \cdot 7$.

\section{Superannuated Dons}

AN alternative arrangement to the Federated Superannuation System for Universities receives consideration in a recent working party report, published by the Department of Education and Science. Headed by Sir George Maddex, the party represented a number of associations and committees and the government departments concerned. The alternative scheme which the committee considered is the terminal salary scheme.

The existing FSSU system is based on policies of assurance so that benefits reflect the actual amounts received as salary during an individual's career. This has led, the report maintains, to inadequate pensions. According to the alternative arrangement, a scheme would be adopted under which pension benefits would be directly related to the teacher's salary at retirement, thus giving weight to economic conditions at that particular time. The rates of benefit would be guaranteed, but the contributions would be fixed on a provisional basis. Because of a variety of reservations from members, however, the working party has been unable to make a clear recommendation in favour of either system.

The report includes an examination of the basic differences between terminal salary and insurance policy schemes, and it also considers the implications of tax and the National Insurance graduated pension scheme; the report compares them by working out the benefits in a number of typical cases. On a salary of $\mathfrak{E 2 , 0 0 0}$ a year, for example, assuming a contribution of 5 per cent, the net charge borne by a teacher according to the terminal salary scheme would be $£ 6718 s .4$., whereas according to the existing scheme

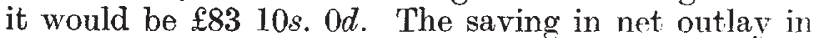
this case is 0.75 per cent of salary.

Figures of future FSSU benefits which are expressed as a percentage of benefits under a terminal salary scheme show that most teachers entering university service for the first time would do better with FSSU; the figures are, however, based on assumptions, certain of which, the report maintains, are of questionable validity. The working party agreed, however, that, if an alternative to the present system is required, the terminal salary scheme is the best that is possible in existing conditions.

\section{Marriage of Convenience}

THE announcement that the British Motor Corporation and Leyland Motors are to merge provides Britain with a motor company of international size. It is also a company with several built-in handicaps, the most serious of which may turn out to be the way in which its factories are scattered about the countryside.
Although this alone is likely to be a limitation on the amount of rationalization that is possible, Sir Donald Stokes, by common agreement the dominant force in the new company, will have plenty of room left for manoeuvre. His principal limitation in the short term is likely to be a shortage of funds, and the $£ 25$ million dowry with which the Industrial Reorganization Corporation blessed the union will come in very useful indeed.

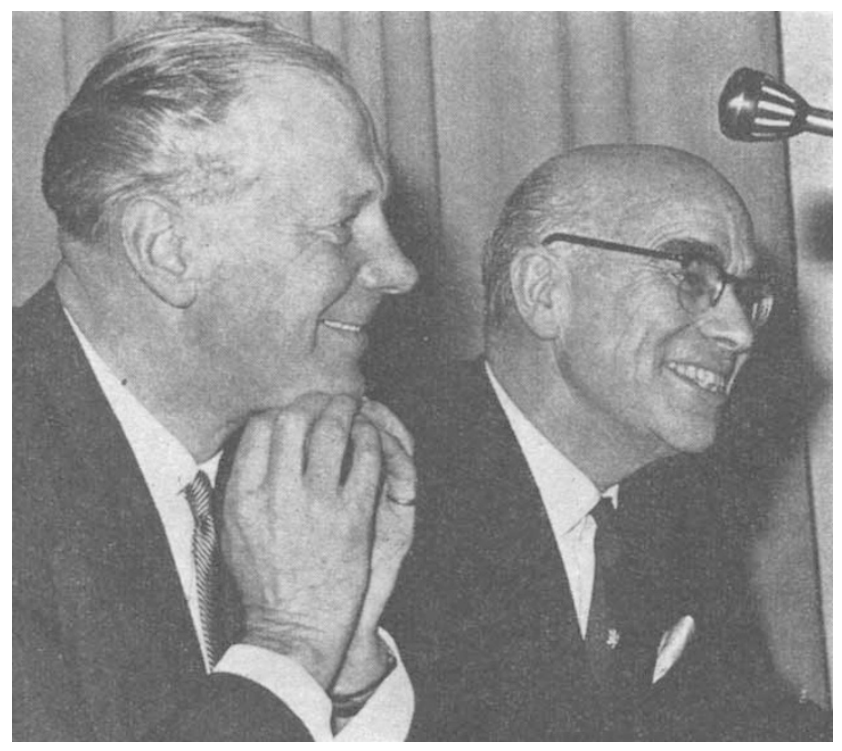

Sir George Harriman (left) and Sir Donald Stokes.

For this reason, it is fortunate that the early decisions Sir Donald, and his Chairman Sir George Harriman, will have to make will involve saving rather than spending money. It is almost certain that BMC's extensive range of cars will be reduced quite rapidly, by the disappearance of the Daimler name and the phasing out of several other models, perhaps including the 1800 . It has been said that the ranges of cars marketed by the two companies are complementary, but this is little more than the traditional incantation which is always murmured when two companies merge. In this case it is simply untrue-there is direct competition both in the sports car and saloon car ranges (the Austin 1300 and the Triumph 1300, for example) and since BMC took over Daimler there is also some overlap in commercial vehicles and coaches. So there is little doubt that some models will have to go; others will have to be introduced to challenge Ford's dominance of the middle of the range. Considerable economies are possible in dealerships and in export organization, and the intervention of Leyland makes it seem more likely that $\mathrm{BMC}$ will at last take advantage of the economies of scale which have been within its grasp since the formation of the Nuffield organization in 1952 .

In research, neither company has anything to match the $\& 1$ million research laboratory which Ford has built. In Leyland, research continues to be done by the individual companies, with Leyland itself perhaps doing the lion's share. It has, for example, built a gas turbine truck, and has pooled its knowledge with Rover, which has also done a good deal of work on gas turbine propulsion. The twin problems of pollution 